\title{
Patterns in size and species diversity of benthic macroinvertebrates in Mediterranean salt marshes
}

\author{
S. Gascón*, D. Boix, J. Sala, X. D. Quintana \\ Institute of Aquatic Ecology, University of Girona, Campus de Montilivi, Facultat de Ciències, 17071 Girona, Spain
}

\begin{abstract}
Mediterranean salt marsh macroinvertebrate assemblages are abiotically filtered due to harsh environmental conditions. We hypothesized that in these environmentally fluctuating systems, biotic interactions would have more relevance than abiotic ones and that size-based interactions would dominate. The manuscript focuses on the response to biotic and abiotic factors of 2 diversity metrics: (1) one that relies on species identity (Shannon-Wiener diversity), and (2) another based on the shape of biomass size spectra (size diversity). Benthic macroinvertebrates (organisms $>1 \mathrm{~mm}$ ) were the target group of this study and were sampled monthly in 6 basins during 2 flooding cycles (from October 1997 to July 1999). The high inter-annual variability characteristic of Mediterranean systems revealed the robustness of the observed patterns. Abiotic and biotic interactions appeared to be significant for both diversity metrics, with species diversity more abiotically controlled than size diversity. The relationships between size diversity and environmental variables were more interannually stable than those for species diversity. Only water total organic carbon had a robust relationship with species diversity, but dissolved inorganic nitrogen and predatory pressure had a robust relationship with size diversity. Additionally, size diversity had a significant succession pattern related to days after flooding (time), whereas species diversity did not. Our results suggest that in abiotically filtered environments, macroinvertebrate size-based interactions become especially relevant.
\end{abstract}

KEY WORDS: Biomass size spectra $\cdot$ Biotic factors $\cdot$ Abiotic factors $\cdot$ Benthos $\cdot$ Mixed-effect models

\section{INTRODUCTION}

The Shannon diversity index is the most widely used diversity metric for community studies, and is frequently employed to assess environmental effects on ecosystems (e.g. Terlizzi et al. 2005, Forster et al. 2006, Heino et al. 2007). However, it has been suggested that the challenge is to measure diversity not only with a single measure (such as taxonomic-based indices), but also to incorporate other concepts that offer a complementary perspective (for example giving information about trophic structure), so that our knowledge of ecosystem processes is improved (Purvis \& Hector 2000).

Body size is among the most important attributes of an organism from an ecological and evolutionary point of view (Werner \& Gilliam 1984). Several authors have noted the relationship between body size and physiological and ecological processes (Peters 1983, Schmidt-
Nielsen 1984, Roa \& Quiñones 1998), and therefore the use of body size when studying community structure processes is reliable (Dickie et al. 1987). Moreover, at the community level, biomass size spectra could be parameterized with body mass-trophic level relationships and used to describe the trophic structure (Jennings et al. 2002), which can provide information about the ecosystem functioning. Additionally, the use of body size to study community structuring seems advantageous over the traditional taxonomic approach, since body size can be more directly related to metabolism and energy transfer within communities (Dickie et al. 1987, Fry \& Quiñones 1994, Gaedke \& Kamjunke 2006). Size diversity has been used in this context to describe the shape of biomass size spectra (e.g. Ichinokawa \& Mac Takahashi 2006), and recently, Quintana et al. (2008) published a methodology describing how to obtain a standardized size diversity measure. 
Some studies have reported that salt marshes contain few species compared to other systems like mangroves or seagrass meadows (Bloomfield \& Gillanders 2005). However, low species diversity does not necessarily imply a less structured community. Recent studies on salt marsh zooplankton communities have shown that low species diversity can coincide with high size diversity due to the co-occurrence of different developmental stages of the dominant taxa, each of which has different diets (Brucet et al. 2006). Assuming that diversity is a function of the total range of resources and the degree of specialization of species to parts of that range, as it is postulated in the Niche Diversification Hypothesis (Connell 1978), a high size diversity would indicate a trophic niche segregation within stages of the same species, which is impossible to detect using only a taxonomic approach (Brucet et al. 2006). In accordance with this, a recent study dealing with benthic macroinvertebrate structuring processes in a salt pan suggested that situations with little or no relationship between niche partitioning and relative species abundance occurred (Barbone et al. 2007). On the other hand, it has been suggested that size diversity in brackish water zooplankton communities is mainly related to biotic interactions, such as fish predation or inter-/intraspecific competition, while taxonomic diversity appears to be more sensitive to abiotic factors such as nutrient availability (Badosa et al. 2007). Regarding macroinvertebrate assemblages in Mediterranean salt marshes, some studies have pointed out that the shape of size spectra reflects changes in resource availability, which are difficult to detect using a taxonomic approach (Basset et al. 2004).

The present study aimed to examine the factors affecting taxonomic and size structures of benthic macroinvertebrate assemblages in abiotically filtered environments, taking Mediterranean salt marshes as a case study. Size diversity and species diversity were used for this proposal. The high inter-annual variability of this system makes it an ideal site to test the robustness of the results observed during a wet and a dry year, and so exemplifying 2 contrasting environmental situations characteristic of Mediterranean systems (Quintana 2002, Álvarez-Cobelas et al. 2005). We hypothesized that in these environments, biotic interactions (e.g. predation) would have more relevance than abiotic ones (e.g. salinity), and that size-based interactions would become especially relevant. (1) The harsh environmental conditions characteristic of Mediterranean salt marshes (e.g. variable salinity, water level fluctuations, daily changes in oxygen concentration) would abiotically filter the species present in benthic assemblages. As a result, the species must be adapted to these conditions by having a high range of environmental tolerance, which could imply that abi- otic factors may not act as a structuring force. (2) Taxonomic changes respond to abiotic variability, while changes in the shape of size spectra are related to resource availability (Basset et al. 2004, Barbone et al. 2007). As a consequence, changes in size spectra would reflect biotic interactions, which we expect to be more important for salt marsh macroinvertebrate assemblages than abiotic variability. Thus, this study had 2 main objectives, i.e. to assess (1) whether there is an effect of biotic interactions and abiotic factors on species and size diversity; and (2) which of these 2 approaches (taxon-based or size-based) can be used to reflect the community structure in an abiotically filtered environment with high environmental fluctuations, in which only few species are present.

\section{MATERIALS AND METHODS}

Study site. The Empordà wetlands are located close to the Mediterranean Sea, in the northeast of the Iberian Peninsula (Fig. 1), and are free from tidal influence. The hydrology is characterized by sudden and irregular floods (by rainfall, inputs from rivers or channels, or sea storms), followed by dry periods, when most of the basins become isolated and gradually dry out. The basins under study are depressions between sand bars in salt marshes, where water accumulates. Their depth varies greatly depending on the flooding regime, but they are usually $<1 \mathrm{~m}$ deep (Fig. 2). The basins are flat, and do not communicate directly with the sea. The absence of direct contact with the sea means that small oscillations in the sea level have little influence on these basins. Nevertheless, the basins differ in water permanence, resulting in different typologies: temporary (completely dry every year), semi-permanent (not completely dry every year), and permanent basins (never completely dry). In the Empordà salt marshes, there is a relationship between granulometry and water permanence (Gascón et al. 2005), because permanent and semi-permanent basins have a higher percentage of sand $($ mean $=61.1 \% \pm 34.9 \mathrm{SD})$ than temporary basins $($ mean $=12.8 \% \pm 7.5 \mathrm{SD})(\mathrm{S}$. Gascón unpubl. data).

Sampling procedure and processing. The study was undertaken in 6 basins in the salt marshes of Empordà wetlands from October 1997 to July 1999 during 2 flooding cycles with inter-annual differences in the water column depths of the basins (Gascón et al. 2008): the first flooding cycle (October 1997 to July 1998) had significantly higher water column depths than the second (September 1998 to July 1999). Water, sediment, and macroinvertebrate samples were taken monthly simultaneously from the same sampling sites (Fig. 1). Sampling was carried out until basins became 


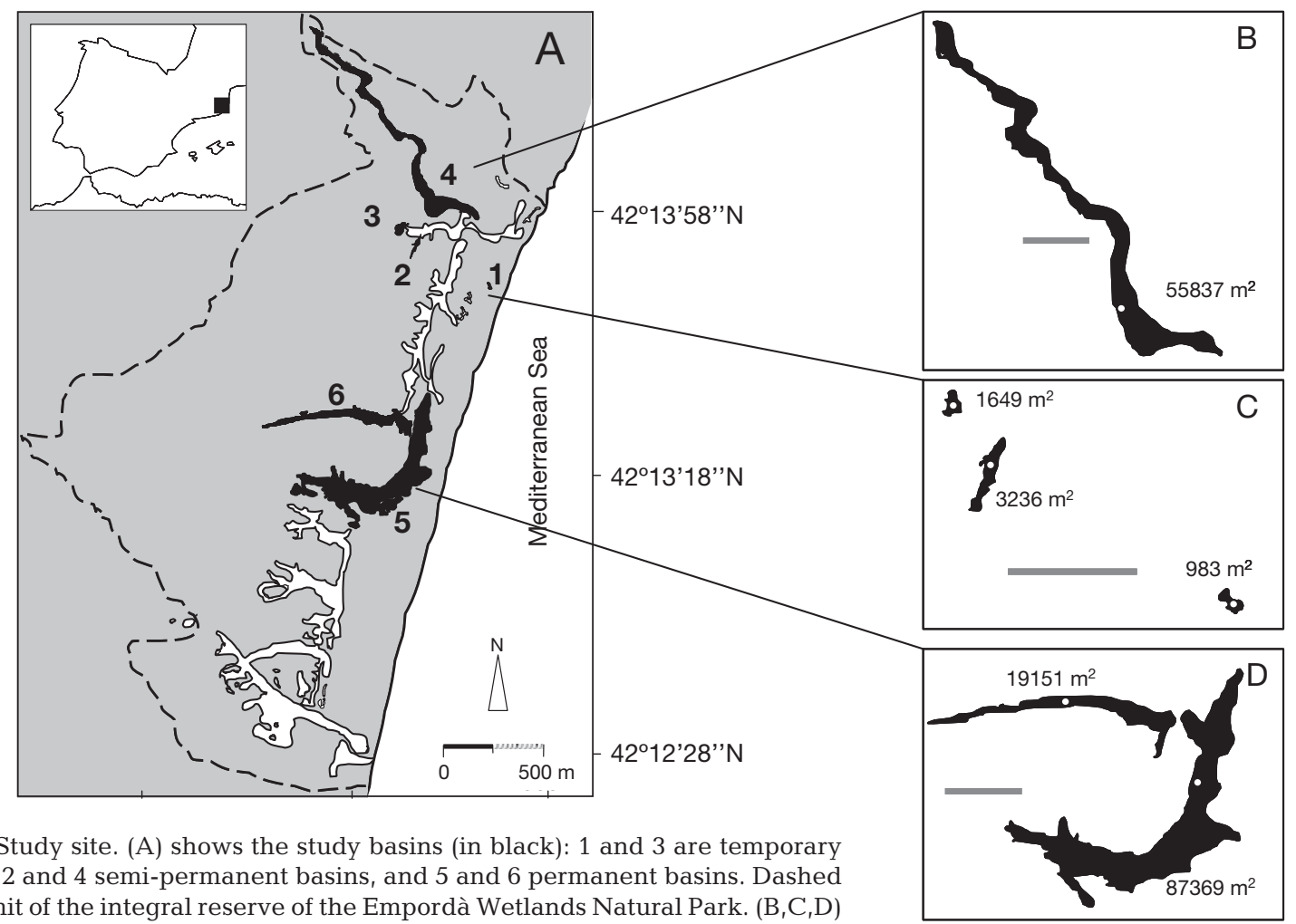

basins, 2 and 4 semi-permanent basins, and 5 and 6 permanent basins. Dashed line: limit of the integral reserve of the Empordà Wetlands Natural Park. $(B, C, D)$

Sampling sites (open circles) and basin surfaces (gray scale bars: $200 \mathrm{~m}$ )

dry. For the permanent basins, sampling sites were exposed during summer drought due to high water level fluctuation.

Water characteristics. Water depth, temperature, and conductivity were obtained in situ. Water depth was measured using a graduate gauge firmly fixed at the bottom of the basins. Conductivity and temperature were measured with a conductivity meter (CRISON 524). One filtered and one unfiltered sample per basin and month) were taken for analyses of dissolved inorganic nutrients (ammonia, nitrite, nitrate, and dissolved reactive phosphorus) and total nitrogen, phosphorus, and organic carbon (total $\mathrm{N}$, total $\mathrm{P}$, TOC), respectively. Dissolved nutrients and total $\mathrm{N}$ and total $\mathrm{P}$ were measured according to standard procedures (Grasshoff et al. 1983). TOC was measured using a TOC analyzer. Water samples were filtered (Whatman GF/C filters), and water chlorophyll a (chl a) content was determined after extraction with $90 \%$ methanol (Talling \& Driver 1963).

Sediment characteristics. Two $5 \mathrm{~cm}$ deep sediment cores with an inner diameter of $1.2 \mathrm{~cm}$ per basin and month) were collected and immediately frozen. Total $\mathrm{N}$ and $\mathrm{C}$ were analyzed using a CHNS-O analyzer. TOC was calculated by subtracting the total inorganic C, obtained by using a calcimetric method $\left(4 \mathrm{~h}\right.$ at $\left.450^{\circ} \mathrm{C}\right)$ and a CHNS-O analyzer, from total $\mathrm{C}$. Total $\mathrm{P}$ of the sediment was measured according to standard procedures (Grasshoff et al. 1983). Detailed information on physical and chemical patterns during the studied period can be found in Gascón et al. (2006).

Macroinvertebrates. Macroinvertebrate samples were obtained using an Ekman grab $\left(225 \mathrm{~cm}^{2}\right)$. Two samples were taken for the smallest basins (1 and 3) and 4 samples for the larger basins $(2,4,5$, and 6$)$ each month (Fig. 1). Organisms were separated alive from the sediment using a $1 \mathrm{~mm}$ mesh size sieve and preserved in $4 \%$ formalin until taxonomic identification. All individuals were identified to species level whenever possible. Abundances were estimated by counting all individuals retained in the sieve. At least 25 individuals for each taxon and sample were randomly chosen for measurements. This number of individuals per taxon and sample ensured that more than $80 \%$ of individuals were measured in at least $50 \%$ of samples. Potential macroinvertebrate predators were identified according to existing literature (Jensen \& André 1993, Tachet et al. 2000, Berezina 2007), counted, and measured. Dry mass was estimated from length or biovolume using existing equations for macroinvertebrates (Gascón et al. 2005 and references therein). Total biomass was obtained by summing the dry biomass of all organisms in each sample. See Table 1 for detailed information on taxa, their abundances, biomass, and identification as potential 

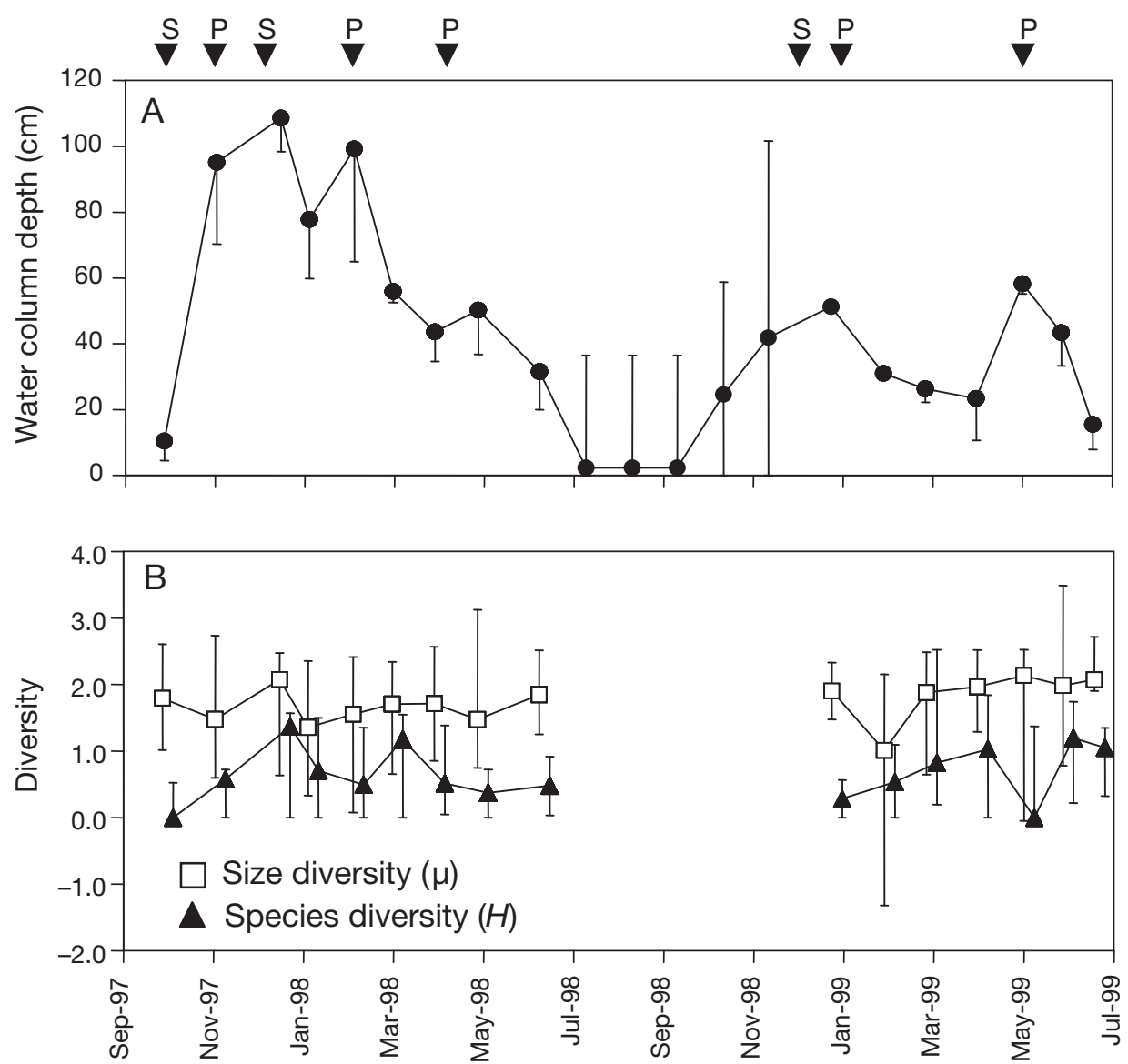

Fig. 2. Temporal pattern of water depth (A), and diversity metrics (B); median, minimum, and maximum values are shown. Hydrological disturbances that occurred during the study $-\mathrm{S}$ : sea storms (waves $\geq 3 \mathrm{~m}$ ); P: intense precipitation events (monthly precipitation $\geq 60 \mathrm{~mm}$ )

predators. In general, macroinvertebrate total richness in the Empordà salt marshes ranged from 18 to 21 taxa, and the assemblages were typically dominated by few species (Gascón et al. 2008).

Species and size diversity metrics. The species and size diversity were calculated for each sample. The species diversity was assessed by means of the Shannon-Wiener index $(H)$ based on the numerical abundance of each identified taxon (Pielou 1969), using the following equation:

$$
H=-\sum_{i=1}^{S}\left(p_{i}\right) \log _{2}\left(p_{i}\right) ; p_{i}=\frac{N_{i}}{N}
$$

where $p_{i}$ is the probability of finding individuals of taxon $i, N_{i}$ is the number of total individuals of taxon $i$, and $N$ is the number of total individuals in the sample. $S$ is the total number of taxa found in that sample.

On the other hand, to asses the size diversity $(\mu)$, we used the non-parametric estimation proposed by Quintana et al. (2008), which was computed based on the Shannon diversity expression adapted for a continuous variable, such as body size. This measure takes the form of an integral involving the probability density function of the size of the individuals described by the following equation:

$$
\mu=-\int_{0}^{+\infty} p_{x}(x) \log _{2} p_{x}(x) d x
$$

where $p_{X}(x)$ is the probability density function of size $x$. Non-parametric kernel estimation was used as a probability density function, after data standardization using division of sample data by their geometric mean value (Quintana et al. 2008).

Statistical analyses. Mixed-effects models provide a flexible and powerful tool to analyze data with both fixed and random effects. The fixed effects are variables (biotic and abiotic) in which we are interested in the parameter estimation, while random effects are used to control the variance structure of the response variables (diversity metrics). In our case, random effects are important because our observational study is hierarchically structured (Crawley 2007), as basins were sampled several times. Moreover, this kind of 
Table 1. Taxa found in more than 1 sample, showing the occurrence (Occ), minimum and maximum, abundance and biomass per sample, and the basin in which each taxon was found. ${ }^{\mathrm{pp}}$ : taxon considered as a potential predator

\begin{tabular}{|c|c|c|c|c|}
\hline & Occ $(\%)$ & Abundance (inds. $10 \mathrm{~cm}^{-2}$ ) & Biomass $\left(\mu \mathrm{g} 10 \mathrm{~cm}^{-2}\right)$ & Basin \\
\hline \multicolumn{5}{|l|}{ Mollusca } \\
\hline Hydrobia acuta & 9.62 & $0.04-0.40$ & $4.02-583.78$ & $1,2,3,4,5$ \\
\hline \multicolumn{5}{|l|}{ Polychaeta } \\
\hline Nereis diversicolor $^{\mathrm{pp}}$ & 71.13 & $0.03-5.73$ & $0.37-11042.12$ & $1,2,3,4,5,6$ \\
\hline Streblospio shrubsolii & 19.67 & $0.04-1.33$ & $3.82-166.22$ & 5,6 \\
\hline Polydora cornuta & 0.84 & $0.04-0.04$ & $15.67-32.39$ & 5 \\
\hline \multicolumn{5}{|l|}{ Oligochaeta } \\
\hline Tubificidae & 2.09 & $0.04-0.17$ & $0.98-634.93$ & $3,4,6$ \\
\hline Nais spp. & 3.35 & $0.04-0.22$ & $25.13-248.03$ & 5,6 \\
\hline Paranais spp. & 7.95 & $0.04-1.28$ & $102.68-1838.59$ & $4,5,6$ \\
\hline \multicolumn{5}{|l|}{ Amphipoda } \\
\hline Corophium orientale & 22.18 & $0.04-23.82$ & $1.34-9127.04$ & $2,5,6$ \\
\hline Gammarus aequicaudapp & 22.59 & $0.02-3.12$ & $1.90-3835.54$ & $1,2,3,4,5,6$ \\
\hline Leptocheirus pilosus & 0.84 & $0.04-0.08$ & $5.50-15.57$ & $\begin{array}{c}1,2,0,4,0,0 \\
5\end{array}$ \\
\hline Orchestia sp. & 0.84 & $0.04-0.04$ & $76.47-84.58$ & 2,3 \\
\hline \multicolumn{5}{|l|}{ Isopoda } \\
\hline Lekanesphaera hookeri & 6.28 & $0.04-0.17$ & $2.04-94.22$ & $4,5,6$ \\
\hline \multicolumn{5}{|l|}{ Coleoptera } \\
\hline Hydroporus planus $^{\mathrm{pp}}$ & 3.35 & $0.04-0.26$ & $210.80-2194.64$ & $1,2,3$ \\
\hline Enochrus bicolor & 2.09 & $0.04-0.13$ & $55.26-1624.83$ & 1,3 \\
\hline \multicolumn{5}{|l|}{ Diptera } \\
\hline Culicoides spp. pp & 2.93 & $0.04-0.22$ & $1.50-8.88$ & $2,3,6$ \\
\hline Chironomus gr. salinarius & 62.34 & $0.04-24.84$ & $1.41-22865.95$ & $1,2,3,4,5,6$ \\
\hline Halocladius varians & 12.13 & $0.04-6.35$ & $5.65-1419.24$ & $1,2,3,4,5,6$ \\
\hline Chloropidae & 5.02 & $0.04-0.13$ & $1.23-36.01$ & $\begin{array}{c}1,2,0,4,0,0 \\
2,4\end{array}$ \\
\hline Scatella sp. 1 & 2.51 & $0.04-2.00$ & $1.29-117.89$ & 1,5 \\
\hline Scatella sp. 2 & 1.67 & $0.08-0.22$ & $2.85-7.71$ & 5 \\
\hline Ephydra spp. & 2.09 & $0.08-2.35$ & $53.03-668.13$ & 1,2 \\
\hline Dolichopodidae ${ }^{p p}$ & 2.51 & $0.04-0.08$ & $5.01-41.44$ & $2,4,6$ \\
\hline
\end{tabular}

analysis allowed us to take into account several particularities derived from our field design and survey, such as basin-to-basin variance, inter-annual variability, heteroscedasticity, and autocorrelation.

Basin-to-basin variance. In mixed models, random effects influence the variance of the response variables (Crawley 2007). In our case, differences among basins could influence diversity values. Moreover, it is particularly useful to consider random effects when 1 or more explanatory variables are correlated due to temporal or spatial pseudoreplication, and consequently, the assumption of independence of errors is not fulfilled. Mixed-effects models deal with this by modeling the covariance structure introduced in the random part of the model (Crawley 2002). Therefore, random effects that come from the same group could be correlated. In our design, several samples were taken per day and per basin, so we had to consider basin and time in the random part of the models.

Inter-annual variability. In all mixed-effects models, flooding cycle was included to study the robustness of the relationships. Thus, when the interaction between each explanatory variable and the flooding cycle had a significant result, the relationship was considered inter-annually variable, because the relationship between the explanatory variable and the diversity metric was not the same for the 2 flooding cycles.

Heteroscedasticity and autocorrelation. Mixedeffects models permit modeling heteroscedasticity of the within-error group (each basin). Thus, 'VarIdent' variance function structure was used to fit heteroscedastic models, thus allowing different variance for each basin. The need for a heteroscedastic model was tested with a likelihood ratio test (Pinheiro \& Bates 2000). The lack of error independence due to temporal autocorrelation was also checked using the autocorrelation function 'ACF' available in the 'nlme' package (Pinheiro et al. 2007). No significant autocorrelations (20 lags and with $\alpha=0.01$ ) were obtained for all tested models, indicating that the normalized residuals resulting for each model behaved like uncorrelated noise.

Mixed-effects models. Linear mixed-effects models were used: (1) to identify environmental variables significantly related to diversity metrics; (2) to study whether the diversity metrics are related to a succession process; and (3) to establish the relationship between the 2 diversity metrics. All linear mixed- 
effects models were calculated with the 'lme' function in the 'nlme' package (Pinheiro et al. 2007).

1) Identification and selection of significant environmental variables: Because splitting variables into biologically meaningful subsets improves interpretability, several variable subsets were created: (1) the physical conditions of the water, (2) nutrient availability in the water, (3) nutrient availability in the sediment, and (4) food web characteristics. Subsets 1, 2, and 3 are related to abiotic factors, while subset 4 is related to biotic factors. Several linear mixed-effects models, 1 for each response variable (species or size diversity), and subset of explanatory variables as fixed effects, were executed. Four models were run: model 1 with variables describing physical conditions of water (water level, temperature, and conductivity); model 2 with variables describing nutrient availability in the water (dissolved inorganic nitrogen [DIN: ammonia+ nitrite+nitrate], dissolved reactive phosphorus, total N, total $\mathrm{P}$, and TOC of the water); model 3 with variables describing nutrient availability in the sediment (total $\mathrm{N}$, total $\mathrm{P}$, and TOC); and model 4 with variables describing food web characteristics (predation pressure and resource availability). Predation pressure was assessed as the ratio between macroinvertebrate potential predator biomass and total macroinvertebrate biomass. Resource availability was estimated as the ratio between water chl $a$ and total biomass. In order to know whether the relationship between size diversity and predation pressure was due to a bias because predators were larger, and thus influenced the size distribution, we carried out another model relating size diversity to the geometric mean of potential predator body size. All models included the basin-to-basin variance structure in the random part of the model. Information on each variable (mean $\pm \mathrm{SD}$ ) for the first and second flooding cycles is provided in Table 2. A natural logarithm was used to transform variables in models 1,2 , and 3 , and a square root transformation was used for the ratios of model 4. All variables were re-calculated subtracting their mean (centered), in order to remove correlations among slopes and intercepts (Pinheiro \& Bates 2000).

Following the principle of parsimony, a model simplification procedure was developed to ascertain that the models contained only significant variables. Thus, a model started with all explanatory variables and interac- tion terms with flooding cycle. The significance of fixed-effect terms was assessed using a conditional $F$ test. Then, the least non-significant term (starting with the interactions) was removed. The significance of the resting fixed-effect terms was re-evaluated by means of the conditional F-test, and if there was another nonsignificant term, a new model that excluded that term was created. The level of significance was also adjusted using the Bonferroni correction for multiple testing, in order to control type I errors. This procedure was repeated until the model contained only significant terms. In addition, non-significant explanatory variables that were included in significant interaction terms were not deleted (Crawley 2002).

Although our models did not indicate which subset was more explanatory, they allowed us to select significant variables within each subset while taking into account all field design particularities. After the variable selection, we used a variation partitioning technique (Borcard et al. 1992) to investigate the relative contribution of each subset of variables (only including significant variables previously identified). The variation partitioning was conducted to determine the contribution of the pure components, extracting the shared variability among subsets. Therefore, after variation partitioning, we obtained the pure effect of each subset and compared their relative importance for each diversity metric. The variation partitioning procedure was carried out with 'varpart' function included

Table 2. Mean (SD) values of the environmental variables considered in this study. Values for the species $(H)$ and size $(\mu)$ diversity are also shown

\begin{tabular}{|lcc|}
\hline & \multicolumn{2}{c|}{ Flooding cycle } \\
& $1997-1998$ & $1998-1999$ \\
\hline Water physical conditions & & \\
Water level $(\mathrm{cm})$ & $50.33(25.83)$ & $36.28(17.34)$ \\
Temperature $\left({ }^{\circ} \mathrm{C}\right)$ & $16.72(5.50)$ & $16.95(5.77)$ \\
Conductivity $\left(\mathrm{mS} \mathrm{cm}^{-1}\right)$ & $27.90(9.96)$ & $30.23(13.28)$ \\
Water nutrient availability $\left(\mathrm{mg} \mathrm{l}^{-1}\right)$ & & \\
Dissolved inorganic nitrogen & $0.12(0.40)$ & $0.11(0.24)$ \\
Dissolved reactive phosphorus & $0.06(0.12)$ & $0.04(0.11)$ \\
Total nitrogen & $2.06(1.39)$ & $1.48(0.96)$ \\
Total phosphorus & $0.25(0.27)$ & $0.18(0.23)$ \\
Total organic carbon & $21.47(17.89)$ & $26.06(22.68)$ \\
Sediment nutrient availability $(\%)$ & & \\
Total nitrogen & $0.19(0.12)$ & $0.23(0.14)$ \\
Total phosphorus & $0.08(0.17)$ & $0.12(0.26)$ \\
Total organic carbon & $2.13(1.48)$ & $2.59(1.61)$ \\
Food web characteristics & & \\
Predation pressure & & $0.52(0.37)$ \\
Resource availability & $0.42(0.36)$ & $0.08(0.30)$ \\
Diversity metrics & $0.06(0.21)$ & \\
$H$ & & $0.86(0.58)$ \\
$\mu$ & $0.71(0.52)$ & $1.80(0.66)$ \\
& $1.53(0.52)$ & \\
\hline
\end{tabular}


in the 'vegan' package (Oksanen et al. 2008) separately by each flooding cycle. This function provides an adjusted coefficient of determination $\left(\mathrm{Adj} \mathrm{R}^{2}\right)$ for each subset of selected variables. This $A d j R^{2}$ is necessary to compare subsets with a different number of variables, correcting the bias in the amounts of variation explained (Peres-Neto et al. 2006).

2) Succession process: To study possible succession processes, a model using the diversity metrics as response variables, days after flooding as the explanatory variable, and basin as a random effect was performed. This model was repeated twice, i.e. once for each diversity metric (species and size diversity). Additionally, to check if the relation of the size diversity metric to a succession process was due to the growth of individuals, we carried out another model relating size diversity to the geometric mean of individual biomass, controlling temporal and spatial autocorrelation.

3) Relationship between the 2 diversity metrics: The relationship between size and species diversity was studied using size diversity as the response variable and species diversity as the explanatory variable, and basin-to-basin variance structure was included in the random part of the model.

All statistical analyses were performed using R 2.5.0 (R Development Core Team 2007). cles indicates that the relationship is not affected by the inter-annual variability.

There was a significant relationship between species diversity and sediment nutrient availability (Table 3). Sediment TOC was significantly related to species diversity, but the relationship was not the same in both flooding cycles (Table 4). Similarly to the case of physical conditions, the inter-annual variability was so high that the relationship changed (Table 4). In contrast, none of the variables used in assessing sediment nutrient availability (model 3) was significantly related to size diversity.

Different patterns were observed for the 2 diversity metrics when food web characteristics were analyzed (model 4). While size diversity showed a non-interannually variable relationship with predation pressure (Tables $3 \& 4$ ), the relationship observed between this variable and species diversity was different for each flooding cycle (Table 3). Again, the inter-annual variability was so high that the relationship changed (Table 4). The relationship found between size diversity and predation pressure was not attributable to a bias due to the body size of predators (i.e. predators being bigger and so influencing the size distribution), because there was no significant relationship between size diversity and the geometric mean of predator body size $\left(F_{1,145}=0.043\right.$;

\section{RESULTS}

All significant relationships between diversity metrics (both size and species diversity) and the physical conditions of the water (model 1) were interannually variable, since there were significant interactions with flooding cycle in all cases (Table 3). Moreover, the inter-annual differences were high enough to cause a change in the relationship, and were always negative for the first flooding cycle and positive for the second (Table 4).

For water nutrient availability (model 2), significant differences in species diversity values were observed between flooding cycles. However, our result showed that the relationship between this metric and TOC in the water was the same for both flooding cycles (Tables 3 \& 4). A significant result was only obtained for size diversity, showing a negative relationship with DIN (Tables $3 \& 4$ ). In this case, the lack of a significant interaction between DIN and the flooding cy-
Table 3. Results of mixed-effects models for the diversity metrics. The significance of fixed-effect terms was assessed using the conditional F-test. ${ }^{*}$ Significant after Bonferroni correction

\begin{tabular}{|c|c|c|c|c|c|}
\hline & & $F$ & df1 & df2 & $\mathrm{p}$ \\
\hline \multicolumn{6}{|c|}{ Water physical conditions (model 1) } \\
\hline \multirow[t]{3}{*}{$\boldsymbol{H}$} & Water temperature (WT) & 23.57 & 1 & 163 & $<0.001^{*}$ \\
\hline & Flooding cycle (FC) & 12.07 & 1 & 163 & $<0.001^{*}$ \\
\hline & $\mathrm{WT} \times \mathrm{FC}$ & 15.17 & 1 & 163 & $<0.001^{*}$ \\
\hline \multirow[t]{5}{*}{$\mu$} & Water column depth (WCD) & 9.26 & 1 & 161 & $0.003^{*}$ \\
\hline & Conductivity (COND) & 8.31 & 1 & 161 & $0.005^{*}$ \\
\hline & Flooding cycle (FC) & 3.06 & 1 & 161 & 0.082 \\
\hline & $\mathrm{WCD} \times \mathrm{FC}$ & 9.17 & 1 & 161 & $0.003^{*}$ \\
\hline & $\mathrm{COND} \times \mathrm{FC}$ & 13.77 & 1 & 161 & $<0.001^{*}$ \\
\hline \multicolumn{6}{|c|}{ Water nutrient availability (model 2) } \\
\hline \multirow[t]{2}{*}{$\boldsymbol{H}$} & Total organic carbon (TOC) & 4.31 & 1 & 164 & 0.040 \\
\hline & Flooding cycle (FC) & 7.40 & 1 & 164 & $0.007^{*}$ \\
\hline & Dissolved Inorganic Nitrogen (DIN) & 8.19 & 1 & 165 & $0.005^{*}$ \\
\hline \multicolumn{6}{|c|}{ Sediment nutrient availability (model 3) } \\
\hline \multirow[t]{3}{*}{$\boldsymbol{H}$} & Total organic carbon (TOC) & 4.70 & 1 & 163 & 0.032 \\
\hline & Flooding cycle (FC) & 11.94 & 1 & 163 & $0.001^{*}$ \\
\hline & $\mathrm{TOC} \times \mathrm{FC}$ & 11.31 & 1 & 163 & $0.001^{*}$ \\
\hline \multicolumn{6}{|c|}{ Food web characteristics (model 4) } \\
\hline \multirow[t]{3}{*}{$\boldsymbol{H}$} & Predation pressure (PP) & 57.26 & 1 & 163 & $<0.001^{*}$ \\
\hline & Flooding cycle (FC) & 3.84 & 1 & 163 & 0.088 \\
\hline & $\mathrm{PP} \times \mathrm{FC}$ & 16.41 & 1 & 163 & $0.001^{*}$ \\
\hline \multirow[t]{4}{*}{$\mu$} & Predation pressure (PP) & 46.96 & 1 & 162 & $<0.001^{*}$ \\
\hline & Resource availability (RA) & 4.01 & 1 & 162 & 0.047 \\
\hline & Flooding cycle (FC) & 1.35 & 1 & 162 & 0.246 \\
\hline & $\mathrm{RA} \times \mathrm{FC}$ & 19.39 & 1 & 162 & $<0.001^{*}$ \\
\hline
\end{tabular}


Table 4. Slope values for each flooding cycle of variables retained in each mixed-effects model (1: water physical conditions; 2: water nutrient availability; 3: sediment nutrient availability; and 4: food web characteristics) and each diversity metric (size diversity: $\mu_{i}$ and species diversity: $H$ ). Explanatory variables are defined in Table 3 . The $t$-test obtained from each mixed-effects model, indicating the significance of the differences between slopes, is also shown. ${ }^{*}$ Significant after Bonferroni correction

\begin{tabular}{|c|c|c|c|c|c|c|c|c|}
\hline Model & $\begin{array}{l}\text { Diversity } \\
\text { metric }\end{array}$ & $\begin{array}{l}\text { Explanatory } \\
\text { variable }\end{array}$ & 1997-1998 & $\begin{array}{l}\text { Clope } \\
\text { 1998-1999 }\end{array}$ & Overall & $t$-Student & $\mathrm{df}$ & $\mathrm{p}$ \\
\hline 1 & $\begin{array}{l}H \\
\mu\end{array}$ & $\begin{array}{c}\mathrm{WT}^{\mathrm{a}} \\
\mathrm{WCD}^{\mathrm{a}} \\
\mathrm{COND}^{\mathrm{a}}\end{array}$ & $\begin{array}{l}-0.64 \\
-0.23 \\
-0.51\end{array}$ & $\begin{array}{l}0.13 \\
0.20 \\
0.39\end{array}$ & $\begin{array}{l}- \\
- \\
-\end{array}$ & $\begin{array}{l}3.89 \\
3.03 \\
3.71\end{array}$ & $\begin{array}{l}163 \\
161 \\
161\end{array}$ & $\begin{array}{c}<0.001^{*} \\
0.003^{*} \\
<0.001^{*}\end{array}$ \\
\hline 2 & $\begin{array}{l}H \\
\mu\end{array}$ & $\begin{array}{l}\text { TOC }^{\mathrm{c}} \\
\text { DIN }^{\mathrm{c}}\end{array}$ & $\begin{array}{l}- \\
-\end{array}$ & $\begin{array}{l}- \\
-\end{array}$ & $\begin{array}{l}-0.13 \\
-0.07\end{array}$ & $\begin{array}{l}0.50 \\
0.76\end{array}$ & $\begin{array}{l}163 \\
163\end{array}$ & $\begin{array}{l}0.617 \\
0.446\end{array}$ \\
\hline 3 & $H$ & $\mathrm{TOC}^{\mathrm{a}}$ & 0.22 & -0.26 & - & -3.36 & 163 & $0.001^{*}$ \\
\hline 4 & $\begin{array}{l}H \\
\mu\end{array}$ & $\begin{array}{l}\mathrm{PP}^{\mathrm{a}} \\
\mathrm{RA}^{\mathrm{b}} \\
\mathrm{PP}^{\mathrm{c}}\end{array}$ & $\begin{array}{c}0.79 \\
-0.45 \\
-\end{array}$ & $\begin{array}{c}-0.04 \\
-2.47 \\
-\end{array}$ & $\begin{array}{c}- \\
- \\
0.66\end{array}$ & $\begin{array}{l}-4.05 \\
-5.35 \\
-1.49\end{array}$ & $\begin{array}{l}163 \\
162 \\
161\end{array}$ & $\begin{array}{c}<0.001^{*} \\
<0.001^{*} \\
0.136\end{array}$ \\
\hline
\end{tabular}

$\mathrm{p}=0.835)$. Size diversity was also significantly related to resource availability (Table 3 ), and although some inter-annual variability was detected, it did not cause the relationship to change (Table 4).

Variation partitioning results showed that biotic interactions were the most explanatory component for size diversity, while abiotic factors informing about physical water characteristics were the second-most important component (Table 5). The importance of water nutrient availability remained almost undetectable for size diversity. The relative importance of these components to size diversity was robust to the inter-annual variability, because in both flooding cycles, biotic interactions explained the highest amount of variance. In contrast, species diversity showed inter-annually variable patterns (Table 5). For example, biotic interactions were the more explicative component for the first flooding cycle, but their relative importance decreased in the following flooding cycle, and sediment TOC became the most explicative component. Nevertheless, variation partitioning results show the strong effect of biotic interactions, especially for size diversity.

Changes in diversity metrics were not coincident with hydrological disturbances (Fig. 2). However, our results showed a significant positive relationship between size diversity and succession pattern, which was assessed using days after flooding as the explanatory variable (Table 6).
This relationship was the same for both flooding cycles, since a nonsignificant interaction existed between days after flooding and flooding cycle. The succession pattern observed in size diversity was not significantly related to the geometric mean of individual biomass $\left(F_{1,165}=0.561 ; \mathrm{p}=0.455\right)$. As a consequence, the succession pattern observed in size diversity could not be ascribed to the growth of individuals, because a significant increase in average sizes of individuals was not observed along succession (Fig. 3). On the other hand, species diversity did not show a succession pattern, because no significant relationship was found between this metric and days after flooding. Nevertheless, both diversity metrics showed interannual variability (Table 6).

Despite the inter-annual variability observed, a significant positive relationship (slope $=0.42 ; \mathrm{SE}=0.065$;

Table 5. The pure explained variation of each variable subset containing only significant variables selected on regression models (1: water physical conditions; 2: water nutrient availability; 3 : sediment nutrient availability; 4 : food web characteristics). An unbiased estimator of each component (AdjR ${ }^{2} ; 0$ to 1 ) is shown. Significance was obtained after Monte Carlo permutation tests (199 permutations; $\left.{ }^{*} \mathrm{p}<0.1,^{* *} \mathrm{p}<0.05,{ }^{* * *} \mathrm{p}<0.001\right)$. Explanatory variables are defined in Table 3

\begin{tabular}{|c|c|c|c|c|c|c|}
\hline \multirow{2}{*}{$\begin{array}{l}\text { Model } \\
1\end{array}$} & \multicolumn{3}{|c|}{$\begin{array}{l}\text { Species diversity }(H) \\
1997-1998 \text { 1998-1999 }\end{array}$} & \multicolumn{3}{|c|}{$\begin{array}{l}\text { Size diversity }(\mu) \\
\quad 1997-1998 \quad 1998-1999\end{array}$} \\
\hline & WT & $0.030^{* *}$ & -0.008 & $\mathrm{WCD}+\mathrm{COND}$ & $0.075^{* * *}$ & $0.095^{* * *}$ \\
\hline 2 & TOC & 0.002 & -0.010 & DIN & $0.017^{*}$ & 0.006 \\
\hline 3 & TOC & $0.023^{* *}$ & $0.265^{* * *}$ & - & - & - \\
\hline 4 & PP & $0.207^{* * *}$ & $0.052^{*}$ & $\mathrm{PP}+\mathrm{RA}$ & $0.202^{* * *}$ & $0.441^{* * *}$ \\
\hline
\end{tabular}


$\left.F_{1,165}=6.560 ; \mathrm{p}<0.0001\right)$ was detected between the 2 diversity metrics (size diversity and species diversity), which was the same for both flooding cycles (Fig. 4A). Thus, size spectra that were highly dominated by few size classes were expected at low species diversity values (e.g. Fig. 4B), while at higher species diversity values, wide ranges of size classes that were not clearly dominated by few size classes were expected (e.g. Fig. 4C).

\section{DISCUSSION}

\section{Importance of biotic interactions and abiotic factors}

Three types of explanatory variables were distinguished according to the relationship observed with the diversity metrics: (1) those that did not show any significant relationship, which indicates that they had no relationship with the diversity metric, (2) those with a significant relationship that was inter-annually variable (significant interaction with flooding cycle), and (3) those with a significant relationship that was not inter-annually variable (interaction with flooding cycle was not significant).

Inter-annually variable relationships were detected for both size and species diversity. Moreover, variation partitioning analyses showed that the relative importance of factors affecting species diversity also changed between flooding cycles, which is not the case for size diversity. In this sense, a previous study conducted in the same salt marshes, which analyzed the effect of a severe drought that occurred between the flooding cycles considered here, concluded that the severe drought affected both the relative abundances and the taxonomic composition of macrobenthic fauna, and as a consequence, the species diversity values changed (Gascón et al. 2007a). Therefore, the observed interannual variability of the relationships established with species diversity may be explained by some particularities related to the different effects of the studied period on environmental processes that directly affected species composition, which made them poorly generalized. For example, the severe drought between the studied flooding cycles caused a decrease in the abun-

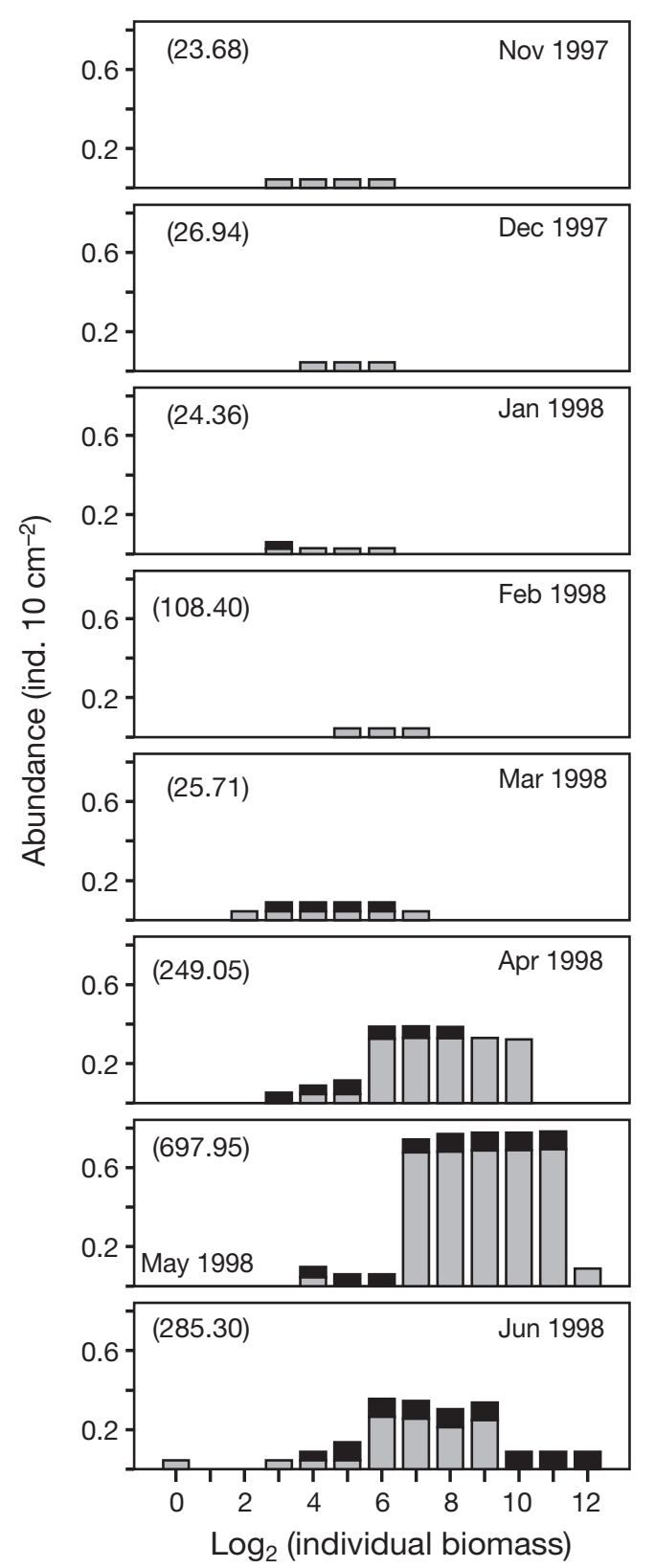

Fig. 3. Size spectra changes over time. The size spectra shown correspond to the macroinvertebrate assemblage of basin 1 during the first flooding cycle (1997-1998). The geometric mean of body size $(\mu \mathrm{g})$ is shown in brackets. Potential predator biomass in black, non-predator biomass in grey

Table 6. Results of mixed-effects models for the diversity metrics and succession pattern, assessed using days after flooding. The significance of fixed-effect terms was assessed using the conditional F-test. NS: not significant

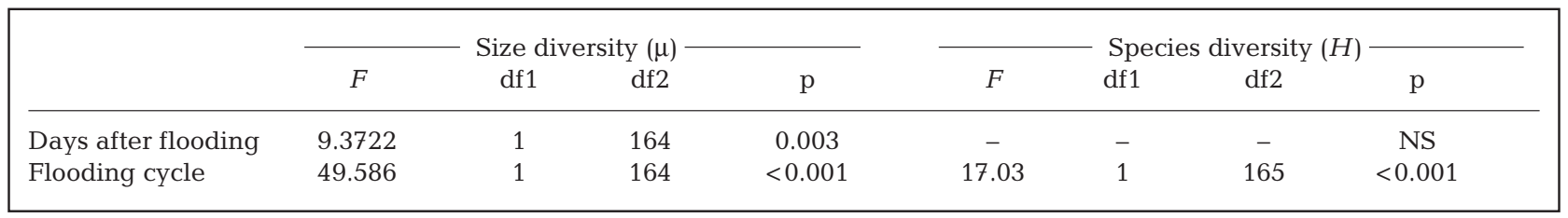



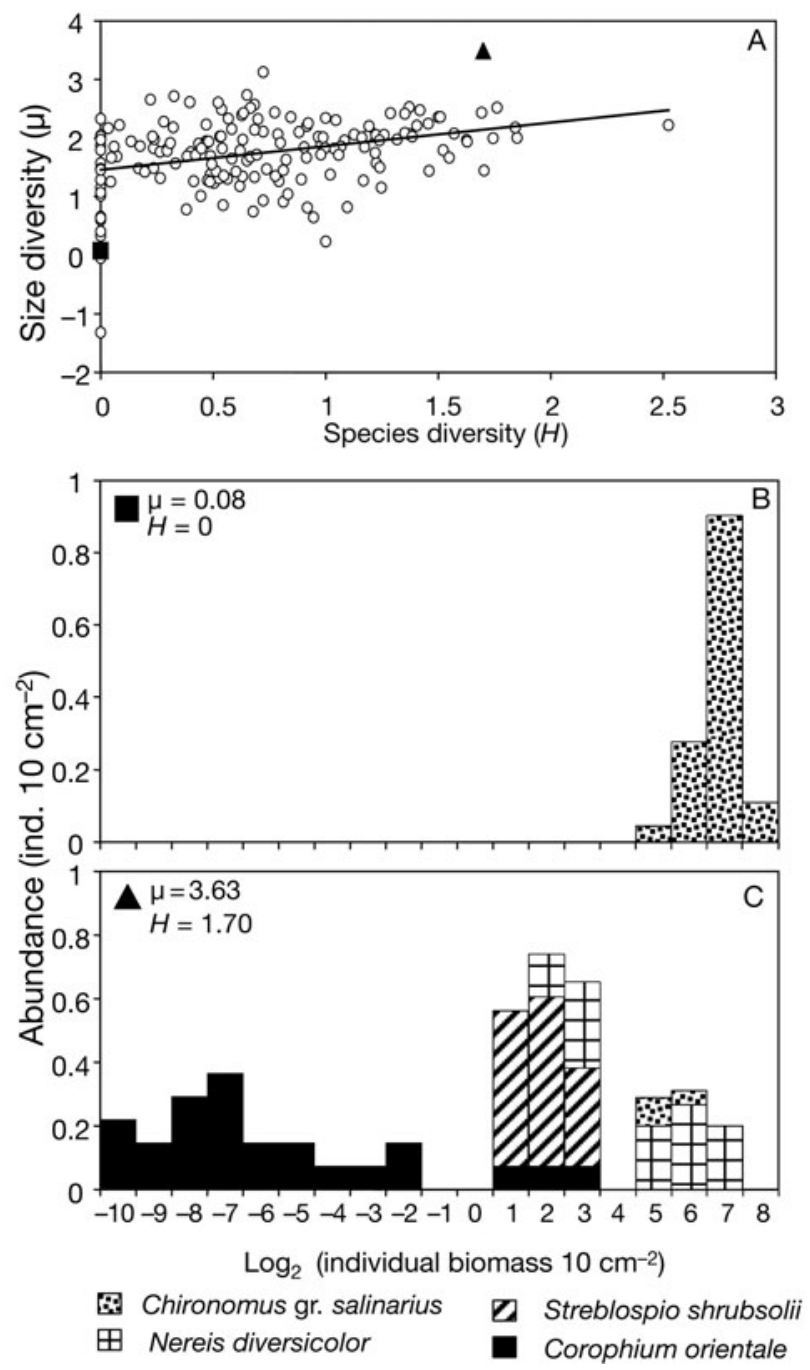

Fig. 4. (A) Relationship between size $(\mu)$ and species diversity $(H)$. (B) and (C) show examples of the size spectra for 2 contrasting situations. The 2 situations are shown in $(\mathrm{A})$ with a triangle and a square

dance of organisms without adaptations to survive or avoid desiccation (Gascón et al. 2008). On the other hand, an inter-annual variability effect on size diversity was only detected in the relationship established with the physical conditions of the water (depth and conductivity). Inter-annual differences between the studied flooding cycles for these variables have been previously analyzed. During the dry flooding cycle, water levels were significantly lower, and the desiccation process was more extreme, implying a higher increase in conductivity in the final part of the hydroperiod compared to the wet flooding cycle (Gascón et al. 2008). This combination of characteristics may lead to different relationships with size diversity that may be also site specific, and so of local interest.
In contrast, relationships of the third type that showed no inter-annual changes may be considered robust to the environmental particularities that occurred during our study period, and so generalized patterns could be deduced. In this sense, only water TOC showed a robust relationship with species diversity, while days after flooding, DIN, and predatory pressure showed a robust relationship with size diversity.

The negative response of species diversity to water TOC may be explained because this system had benthic assemblages characterized by a high dominance of few species during stable conditions (Gascón et al. $2007 b)$, mainly at the end of flooding cycles when a high level of TOC in water was also reported (Gascón et al. 2006). In these conditions, high TOC values and low species diversities are not related to productive events during water and nutrient inputs, but to concentration episodes due to evaporation during confinement.

Size diversity responded negatively to increases in DIN. These salt marshes have low nitrogen/phosphorus ratios, which link the availability of dissolved nitrogen to production (Quintana et al. 1998). Thus, this negative relationship could be a consequence of a decrease in size diversity with productivity. Similar relationships between size distribution and nutrient availability have also been reported in stream benthic communities (Morin et al. 2001). According to this work, sites with high nutrient availability show a similar range of sizes but with a higher dominance of a few sizes (that is, with a low size diversity).

Size diversity is the only diversity metric that had an inter-annually robust response to any of the biotic factors analyzed. Our results showed that benthic size diversity increased with predation pressure, which supports the extended idea that body size differences are important for the strength and type of interaction among species (e.g. Woodward \& Hildrew 2002). Surprisingly, previous work that focused on zooplankton communities found the opposite pattern to our results (Badosa et al. 2007). However, the predation effect in that study was due to fish predation, that is, caused by organisms of a higher trophic level that were not included in the size distribution analyzed. In contrast, the predation pressure analyzed herein was due to macroinvertebrate predation, and therefore was included in the size distribution analyzed. These differences suggest that predation may cause 2 opposite effects on size distribution. Predation by organisms of a higher trophic level may narrow the size structuring of the predated assemblage by removing individuals of specific sizes (generally the largest). However, our results showed that macroinvertebrate predation may favor a size-structured assemblage, with a broader size spectrum not dominated by particular sizes, thus implying higher size diversity values. Accordingly, 
Woodward \& Hildrew (2002), studying intraguild predation effects, demonstrated that larger predators used prey from a larger size spectrum, hence they would potentially affect several prey sizes, producing a broadening of the overall size spectrum.

The relationships between diversity metrics and water nutrient availability were not significant on their own, because when all environmental variables were taken into account (variation partitioning results) water nutrient availability did not significantly explain any portion of benthic diversity variability observed for both species and size approaches. In contrast, food web characteristics were significant on their own, in both flooding cycles and for both diversity metrics. This result may suggest that, as we expected, biotic interactions are significant structuring forces in these abiotically filtered systems.

\section{Community structuring processes}

The positive correlation found between size diversity and the number of days after flooding agrees with a progressive increase in size diversity during succession, which is not observable in the species diversity pattern. This suggests that macrobenthic assemblages of these coastal lagoons tend to have progressive structuring based on size distribution rather than on species composition. The relationship between size diversity and productivity (DIN) suggested above also supports this interpretation. This progressive structuring is not linked to a biomass increase of individuals, since no significant relationship was found between size diversity and population biomass. Similar patterns have been described for zooplankton communities in the same type of ecosystems, with strong decreases in species diversity and increases in size diversity during succession (Brucet et al. 2006).

It has been pointed out that species diversity influences the functioning of the overall ecosystem (Hector \& Bagchi 2007). However, using it to describe functional processes may be misleading, because the taxonomic identity of organisms is not necessarily related to their functional role. Our results showed inconsistent patterns between species diversity values and biotic factors. It has been argued that this relation does not occur for several reasons, such as primary control by abiotic factors, dominance of ecosystem effects by a single species that was not removed, or strong overlap of resources used by different species (Hooper et al. 2005 and references therein). In our study, the third explanation seems the most plausible, because many abundant species such as Nereis diversicolor, Chironomus salinarius, and Gammarus aequicauda can feed on detritus, and so had some niche overlap. This find- ing is in accordance with Barbone et al. (2007), who also described a lack of relationship between relative abundance and niche-partitioning of salt pan macroinvertebrate species. This overlap is not unique to Mediterranean salt marshes, because organisms inhabiting abiotically filtered environments tend to have niche overlaps (e.g. Statzner et al. 2004).

Several studies have already recognized the importance of body size in food web functioning (e.g. Dickie et al. 1987, Ichinokawa \& Mac Takahashi 2006). Our study suggests that size diversity is more sensitive to biotic factors than species diversity is, as is the case for zooplankton communities in these ecosystems (Badosa et al. 2007). Moreover, the relationships established between food web descriptors with the size-based approach were more inter-annually stable than with the taxonomic approach. Accordingly, a previous study stated that body-size abundance distributions are less variable than taxonomic composition (Basset et al. 2004). As a consequence in abiotically filtered environments, dominated by few tolerant species, size-based interactions become especially relevant because they give a complementary understanding of the processes dealing with community structuring.

Acknowledgements. This work was supported by a grant from the Comisión de Investigación Científica y Técnica (CICYT), Programa de Recursos Naturales (ref. CGL200805778/BOS). R. Feller provided useful comments on a previous version of the manuscript and helped to improve the English. We also thank anonymous referees for their valuable suggestions and comments.

\section{LITERATURE CITED}

Álvarez-Cobelas M, Rojo C, Angeler DG (2005) Mediterranean limnology: current status, gaps and the future. J Limnol 64:13-29

> Badosa A, Boix D, Brucet S, López-Flores R, Gascón S, Quintana XD (2007) Zooplankton taxonomic and size diversity in Mediterranean coastal lagoons (NE Iberian Peninsula): influence of hydrology, nutrient composition, food resource availability and predation. Estuar Coast Shelf Sci 71:335-346

Barbone E, Rosati I, Pinna M, Basset A (2007) Taxonomic and dimensional structure of benthic macroinvertebrate guilds in the Margherita di Savoia Salt Pans (Italy). Transit Waters Bull 4:21-31

Basset A, Sangiorgio F, Pinna M (2004) Monitoring with benthic macroinvertebrates: advantages and disadvantages of body size descriptors. Aquat Conserv 14:S43-S58

Berezina N (2007) Food spectra and consumption rates of four amphipod species from the North-West of Russia. Fundam Appl Limnol 168:317-326

> Bloomfield AL, Gillanders BM (2005) Fish and invertebrate assemblages in seagrass, mangrove, saltmarsh, and nonvegetated habitats. Estuaries 28:63-77

Borcard D, Legendre P, Drapeau P (1992) Partialling out the spatial component of ecological variation. Ecology 73: 1045-1055 
Brucet S, Boix D, López-Flores R, Badosa A, Quintana XD (2006) Size and species diversity of zooplankton communities in fluctuating Mediterranean salt marshes. Estuar Coast Shelf Sci 67:424-432

Connell JH (1978) Diversity in tropical rain forests and coral reefs - high diversity of trees and corals is maintained only in a non-equilibrium state. Science 199:1302-1310

Crawley MJ (2002) Statistical computing. An introduction to data analysis using S-Plus. John Wiley \& Sons, Chichester

Crawley MJ (2007) The R book. John Wiley \& Sons, Chichester

Dickie LM, Kerr SR, Boudreau PR (1987) Size-dependent processes underlying regularities in ecosystem structure. Ecol Monogr 57:233-250

Forster RM, Creach V, Sabbe K, Vyverman W, Stal LJ (2006) Biodiversity-ecosystem function relationship in microphytobenthic diatoms of the Westerschelde estuary. Mar Ecol Prog Ser 311:191-201

Fry B, Quiñones RB (1994) Biomass spectra and stable isotope indicators of trophic level in zooplankton of the Northwest Atlantic. Mar Ecol Prog Ser 112:201-204

Gaedke U, Kamjunke N (2006) Structural and functional properties of low- and high-diversity planktonic food webs. J Plankton Res 28:707-718

Gascón S, Boix D, Sala J, Quintana XD (2005) Variability of benthic assemblages in relation to the hydrological pattern in Mediterranean salt marshes (Empordà wetlands, NE Iberian Peninsula). Arch Hydrobiol 163:163-181

- Gascón S, Boix D, Sala J, Quintana XD (2006) Organic carbon and nutrient $(\mathrm{P}, \mathrm{N})$ concentrations of water and sediment in several aquatic environment types of a Mediterranean coastal wetland (Empordà Wetlands, NE Iberian Peninsula). Ann Limnol-Int J Limnol 42:221-231

Gascón S, Boix D, Sala J, Quintana XD (2007a) Changes on macrobenthic fauna of a Mediterranean salt marsh (Emporda wetlands, NE Iberian Peninsula) after a severe drought, with special emphasis on the Corophium orientale population. Vie Milieu 57:3-12

> Gascón S, Brucet S, Sala J, Boix D, Quintana XD (2007b) Comparison of the effects of hydrological disturbance events on benthos and plankton salt marsh communities. Estuar Coast Shelf Sci 74:419-428

Gascón S, Boix D, Sala J, Quintana XD (2008) Relation between macroinvertebrate life strategies and habitat traits in Mediterranean salt marsh ponds (Empordà wetlands, NE Iberian Peninsula). Hydrobiologia 597:71-83

Grasshoff K, Ehrhardt M, Kremling K (1983) Methods of seawater analysis. Verlag Chemie, Weinheim

Hector A, Bagchi R (2007) Biodiversity and ecosystem multifunctionality. Nature 448:188-190

Heino J, Mykrä H, Hämäläinen $\mathrm{H}$, Aroviita J, Muotka T (2007) Responses of taxonomic distinctness and species diversity indices to anthropogenic impacts and natural environmental gradients in stream macroinvertebrates. Freshw Biol 52:1846-1861

Hooper DU, Chapin FS, Ewel JJ, Hector A and others (2005) Effects of biodiversity on ecosystem functioning: a consensus of current knowledge. Ecol Monogr 75:3-35

Ichinokawa M, Mac Takahashi M (2006) Size-dependent carbon flow in the epipelagic food web of the Western Equatorial Pacific. Mar Ecol Prog Ser 313:13-26

> Jennings S, Pinnegar JK, Polunin NVC, Warr KJ (2002) Linking size-based and trophic analyses of benthic community structure. Mar Ecol Prog Ser 226:77-85

Jensen KT, André C (1993) Field and laboratory experiments on interactions among an infaunal polychaete, Nereis diversicolor, and two amphipods, Corophium volutator \& C. arenarium: effects on survival, recruitment and migration. J Exp Mar Biol Ecol 168:259-278

Morin A, Bourassa N, Cattaneo A (2001) Use of size spectra and empirical models to evaluate trophic relationships in streams. Limnol Oceanogr 46:935-940

Oksanen J, Kindt R, Legendre P, O'Hara B, Simpson GL, Solymos P, Stevens MHH, Wagner H (2008) vegan: community ecology package. R Foundation for Statistical Computing. $\mathrm{R}$ package version $1.16-2$

> Peres-Neto PR, Legendre P, Dray S, Borcard D (2006) Variation partitioning of species data matrices: estimation and comparison of fractions. Ecology 87:2614-2625

Peters RH (1983) The ecological implications of body size. Cambridge University Press, Cambridge

Pielou EC (1969) An introduction to mathematical ecology. Wiley-Interscience, New York

Pinheiro JC, Bates DM (2000) Mixed-effects models in S and S-PLUS. Springer-Verlag, New York

Pinheiro JC, Bates DM, DebRoy S, Sarkar D (2007) nlme: linear and nonlinear mixed effects models. R Foundation for Statistical Computing. R package version 3

> Purvis A, Hector A (2000) Getting the measure of biodiversity. Nature 405:212-219

Quintana XD (2002) Estimation of water circulation in a Mediterranean salt marsh and its relationship with flooding causes. Limnética 21:25-35

> Quintana XD, Moreno-Amich R, Comín FA (1998) Nutrient and plankton dynamics in a Mediterranean salt marsh dominated by incidents of flooding. Part 1: Differential confinement of nutrients. J Plankton Res 20:2089-2107

Quintana XD, Brucet S, Boix D, López-Flores R and others (2008) A non-parametric method for the measurement of size diversity, with emphasis on data standardisation. Limnol Oceanogr Methods 6:75-86

R Development Core Team (2007) R: a language and environment for statistical computing. R Foundation for Statistical Computing, Vienna

Roa R, Quiñones RA (1998) Theoretical analysis of the relationship between production per unit biomass and animal body size. Oikos 81:161-167

Schmidt-Nielsen K (1984) Scaling: Why is animal size so important? Cambridge University Press, Cambridge

Statzner B, Doledec S, Hugueny B (2004) Biological trait composition of European stream invertebrate communities: assessing the effects of various trait filter types. Ecography $27: 470-488$

Tachet H, Richoux P, Bournaud M, Usseglio-Polatera P (2000) Invertébrés d'eau douce: systématique, biologie, écologie. CNRS Éditions, Paris

Talling JF, Driver D (1963) Some problems in the estimation of chlorophyll a in phytoplankton. In: Doty MS (ed) Proceedings of the Conference on Primary Productivity Measurement, Marine and Freshwater. University of Hawaii, Honolulu: USA Atomic Energy Commission, Division of Technical Information TID 7633, p 142-146

Terlizzi A, Scuderi D, Fraschetti S, Anderson MJ (2005) Quantifying effects of pollution on biodiversity: a case study of highly diverse molluscan assemblages in the Mediterranean. Mar Biol 148:293-305

> Werner EE, Gilliam JF (1984) The ontogenetic niche and species interactions in size structured populations. Annu Rev Ecol Syst 15:393-425

> Woodward G, Hildrew AG (2002) Body-size determinants of niche overlap and intraguild predation within a complex food web. J Anim Ecol 71:1063-1074

Submitted: October 28, 2008; Accepted: June 9, 2009

Proofs received from author(s): September 19, 2009 